\title{
Changes in thickness of each layer of developing chicken cornea after administration of caffeine
}

\author{
Monika Kujawa-Hadryś, Dariusz Tosik, Hieronim Bartel \\ Department of Histology and Tissue Ultrastructure, Medical University of Łódź, Poland
}

\begin{abstract}
The aim of the study was the presentation of changes in thickness of each layer of a developing cornea, that came into being under an influence of caffeine which was administered to chicken embryos. Research materials were 26 chicken embryos from breeding eggs that had been incubated. Breeding eggs were divided into two groups: control ( $\mathrm{n}=30)$ in which Ringer liquid was given, and experimental $(\mathrm{n}=30)$ in which teratogenic dose of caffeine was administrated $-3.5 \mathrm{mg} / \mathrm{egg}$. In $36^{\text {th }}$ hour of incubation solutions were given with cannula through a hole in an egg shell directly onto amniotic membrane. After closing the hole with paraffin, eggs were put back into incubator. On $10^{\text {th }}$ and $19^{\text {th }}$ day of incubation corneas were taken for morphometric and morphological analysis. In experimental groups reduction of corneal thickness, thickening of corneal epithelium and corneal endothelium as well as Bowman's and Descemet's membranes, decrease of thickness of corneal stroma in comparison with the control group have been observed. Caffeine causes thickness changes of all layers and decreases the total thickness of a developing cornea.
\end{abstract}

Key words: caffeine, cornea development, corneal thickness, chicken embryos.

\section{Introduction}

An eye is a complex structure deriving from different sources: the wall of the midbrain, surface ectoderm of the head and mesoderm of neural crest. In an eye development two important processes can be distinguish. First of them is a series of inductive signals leading to origins of most of eye structures. Second process consists of coordinate differentiation of those structures. Influence of adjoining eye elements is vital for correct visual reception [1-4].

Due to the generality of appearance (coffee, tea, chocolate, medicines) caffeine is the most commonly consumed psychostimulators.

In humans caffeine penetrates through placenta getting to amniotic fluid and umbilical cord blood. Next it is present in serum and urine of infant. Human infants have lower level of enzymes that are necessary for caffeine metabolism. Moreover, caffeine dissmission from blood of pregnant woman is delayed and caffeine concentration in a blood of infant is in balance with its

Correspondence: M. Kujawa-Hadryś, Dept. of Histology

and Tissue Ultrastructure, Medical University of Łódź,

Żeligowskiego Str. 7/9, 90-643 Łódź, Poland;

tel./fax.: (+4842) 6324087,

e-mail: monika.kujawa-hadrys@umed.lodz.pl accumulation in mother's blood. Caffeine dismission in infants and embryos is also slowed down which makes, that the given dose of caffeine causes much more intensified effects in embryos than in adults. [5]. Caffeine clearance stays fundamentally unchanged during the first trimester of pregnancy, whereas, in the second, and third trimester decreases significantly. That is why half-life of caffeine in blood of pregnant women is four times longer than in those who are nonpregnant and this period lasts around 2.5 hours. Finally, it leads to an increase of caffeine concentration in blood of pregnant women [6-8].

Mechanism of a destructive caffeine effect on developing embryos is still hypothetical. Caffeine causes an increase of cAMP concentration inside a cell through phosphodiesterases inhibition, what may have an influence on a growth and development of embryo cells [9]. So far only few studies suggest destructive effects of caffeine on some structures of an eye development, especially on a cornea. Changes was specially intensified in corneal anterior epithelium, stroma and endothelium [10].

The aim of the study was the presentation of changes in thickness of each layer of a developing cornea that came into being under an influence of caffeine which was given to chicken embryos. 
Table 1. Characteristics of the effectiveness of incubation in particular groups.

\begin{tabular}{|c|c|c|c|c|c|}
\hline & $\begin{array}{c}\text { Fggs/ } \\
\text { group }\end{array}$ & $\begin{array}{c}\text { Embryos/ } \\
\text { group }\end{array}$ & $\begin{array}{c}\text { Lived } \\
\text { embryos }\end{array}$ & $\begin{array}{c}\text { Death } \\
\text { embryos }\end{array}$ & $\begin{array}{c}\text { No } \\
\text { embryos }\end{array}$ \\
\hline C.10 & 15 & 9 & 8 & 1 & 6 \\
\hline F.10 & 15 & 7 & 5 & 2 & 8 \\
\hline C.19 & 15 & 8 & 7 & 1 & 7 \\
\hline L.19 & 15 & 7 & 6 & 1 & 8 \\
\hline
\end{tabular}

\section{Materials and methods}

Chicken embryos. The research material was 26 chicken embryos from breeding eggs of ROSS 308 strand kept in incubator at the temperature $37-38^{\circ} \mathrm{C}$ and humidity $50-60 \%$. 60 breeding eggs were used in the research. Effectiveness of chicken hatching was about $50-60 \%$. Breeding eggs were randomly divided into two groups. The first group was the control group. In $36^{\text {th }}$ hour of incubation $\left(9 / 10^{\text {th }}\right.$ stage of development according to Hamburger-Hamilton) [11] Ringer solution was injected into 30 eggs from that group. Next 30 eggs of the second, experimental group were given a teratogenic dose of caffeine $-3.5 \mathrm{mg} / \mathrm{egg}$ [12]. Solutions were given with a cannula through holes in eggs shells directly onto amniotic membrane. After closing the hole with paraffin, eggs were put back to incubator. On $10^{\text {th }}$ and $19^{\text {th }}$ day of incubation $\left(36^{\text {th }}\right.$ and $45^{\text {th }}$ stage of development according to Hamburger-Hamilton) corneas were taken for morphometric and morphological analysis. For investigation both right and left corneas only from the living embryos have been used. Living embryos were killed by decapitation. Eyeballs were removed from embryos. Corneas were taken with a use of microsurgical tools and stereo microscope. Specimens were prepared with methods used in electron microscopy. Whole corneas were fixed in a $3.6 \%$ solution of glutaraldehyde for 3 hours, next rinsed in 0.13 molar solution of cacodylic buffer and contrasted in $2 \%$ solution of osmium tetroxide. Then the taken tissues were dehydrated in alcohols of increasing concentration and in propylene oxide and embedded in epoxy resin - Araldite.

So prepared blocks, were cut in diameter plane with a diamond knife into the semithin sections. Afterwards specimens were stained with a toluidin blue solution and subjected to evaluation with optical microscope.

Morphometric analysis. Measurements were performed on three semi-thin cross sections of diameter area of each cornea. They were photographed by use of OLYMPUS BX41 microscope with $40 \times$ lens connected to digital camera OLYMPUS C-5060.

Each section was photographed three times. Depending on a group abundance 45 to 72 photographs of left and right cornea were taken. For the measurements 30 pictures from each group were randomly chosen.

The thickness of following layers of cornea were measured:

- anterior epithelium (AE),

- Bowman's membrane (BM),

- corneal stroma (M),

- Descemet's membrane (DM),

- endothelium (PE),

- cornea thickness (CT).

Thickness of each layer of cornea was measured with use of original software KIDNEY v.1.1. (Fig. 1). Boundaries of each layer were marked with optical mouse. Software algorithm assumes that a measurement of thickness is made if the angle between lines that mark boundaries of layers and section line,

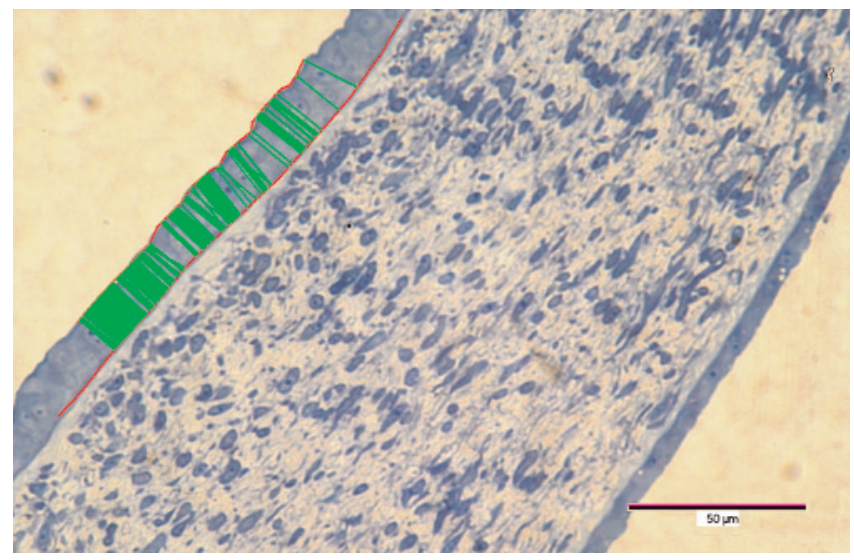

Fig. 1. Method of measurement of the thickness of the anterior epithelium using a computer program "KIDNEY". The thicknesses of other layers were measured in the same way (original magnification $\times 200$ ).

which length represents the distance between the boundaries, is equal $90^{\circ} \pm 3^{\circ}$ [13]. Obtained results were saved in Microsoft Excel spreadsheet to be used in a further statistic analysis.

Statistical analysis. Statistical analysis was carried out with use of Statgraphics Centurion XV software. It covered the calculation of positional parameters as well as the comparison of each group distribution.

Following positional parameters were calculated: average values, standard deviation, coefficient of variation, mode, median, randomness evaluation of the taken sample. Evaluation of normal distribution was performed by use of both $\chi^{2}$ and KolmogorowSmirnow tests. Comparison of the distribution between the groups was carried out with use of non-parametric Mann-Whitney U-test for non-related samples. The differences were treated as significant at the level $\mathrm{p}<0.01$.

\section{Results}

On $10^{\text {th }}$ day of incubation in the control group C.10, 1 dead embryo was observed, while in the respective experimental group E. $10-2$. On $19^{\text {th }}$ day of incubation the number of dead embryos in the control C.19 and experimental group E.19 was 1. Characteristic of examined groups is in table 1 .

No changes of macroscopic structure and size of the living embryos in each group were recorded. Collected on the respective days of incubation corneas of the experimental groups did not show macroscopic differences in comparison to respective control groups. At the light microscopic level, marked reduction in total corneal thickness in the experimental group, compared with control groups, both on $10^{\text {th }}$ and $19^{\text {th }}$ day of incubation was noted (Fig. 2 A,B,C,D). This observation was confirmed with morphometric evaluation, made by the "KIDNEY" software. The total corneal thickness increased with the development. On the $10^{\text {th }}$ day of incubation it was lower than in $19^{\text {th }}$ day of incubation in all groups. General composition of corneal layers was similar in all groups in the respective days of incubation. 

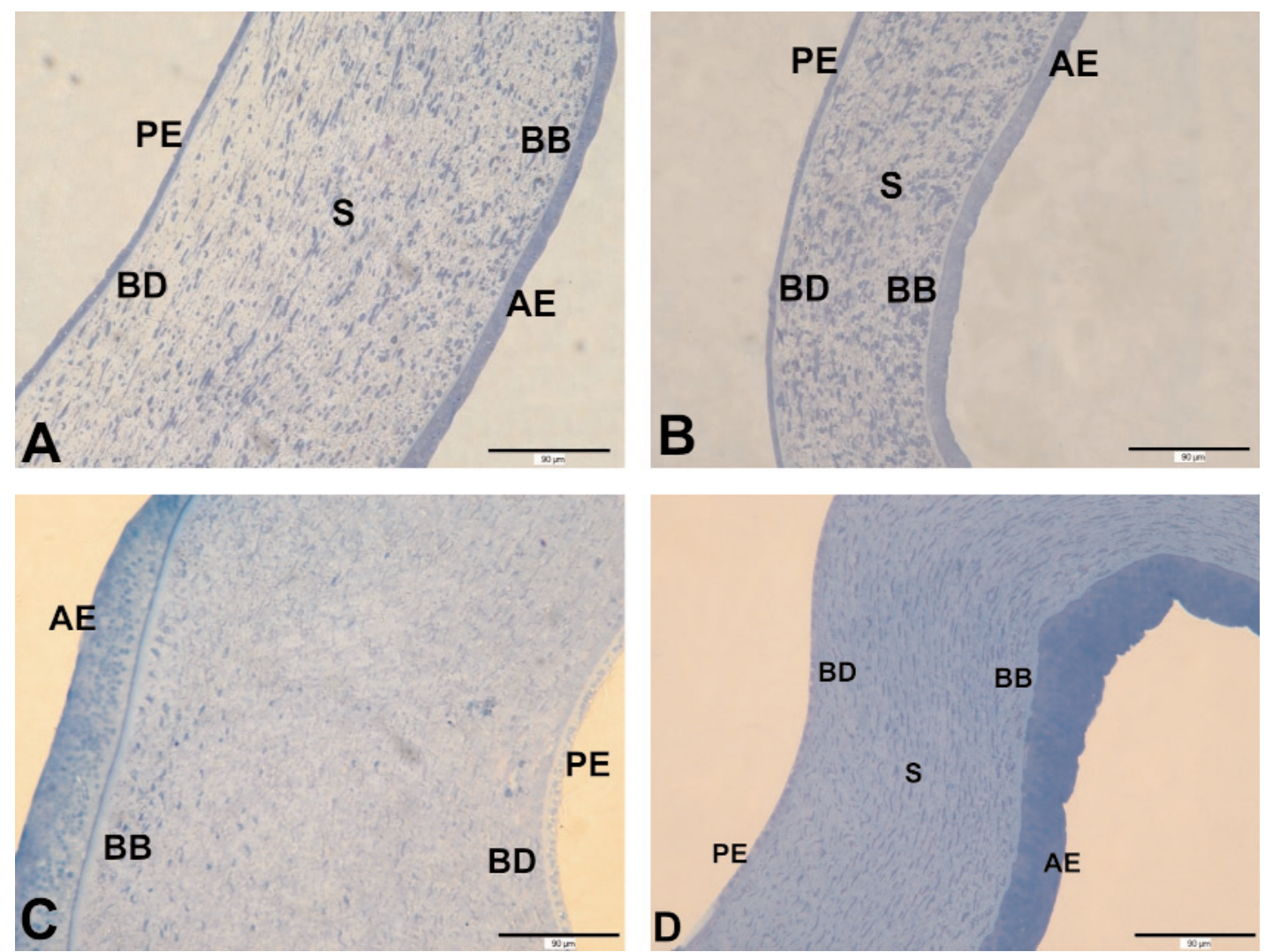

Fig. 2. Semithin sections of cornea. Total thickness of cornea in experimental groups $(\mathrm{E} 10-2 \mathrm{~B}, \mathrm{E} 19-2 \mathrm{D})$ decreases in comparison to respective control groups $(\mathrm{C} 10-2 \mathrm{~A}, \mathrm{C} 19-2 \mathrm{C})$. Additionally, stroma width decreases and density of stromal cells is higher in experimental groups. AE - anterior epithelium, BB - Bowman's membrane, $\mathrm{S}$ - stroma, BD - Descemet's membrane, PE - posterior epithelium (original magnification $\times 200$ ).

In all groups, the anterior epithelium was stratified squamous. Under it Bowman's membrane was present. The corneal stroma was the thickest layer of the cornea. Increased amount of collagen fibers and reduced number of cells in the corneal stroma during the development were observed. Between corneal stroma and the corneal endothelium was Descemet's membrane.

On $10^{\text {th }}$ day an average thickness of epithelium in the control group was $13.00 \mu \mathrm{m}(4.72 \%$ of entire cornea thickness), Bowman's membrane $2.54 \mu \mathrm{m}$ $(0.91 \%)$, stroma $250.06 \mu \mathrm{m}(90.83 \%)$, Descemet's membrane $3.30 \mu \mathrm{m}(1.21 \%)$, endothelium $5.10 \mu \mathrm{m}$ $(1.83 \%)$, entire $275.89 \mu \mathrm{m}$.

On the $10^{\text {th }}$ day an average thickness of epithelium in the experimental group was $14.33 \mu \mathrm{m}(11.57 \%$ of entire cornea thickness), Bowman's membrane 3.87 $\mu \mathrm{m}(4,33 \%)$, stroma $101.38 \mu \mathrm{m}$ (78.20\%), Descemet's membrane $3.05 \mu \mathrm{m}(2.39 \%)$, endothelium $4.46 \mu \mathrm{m}$ (3.19\%), entire $129.02 \mu \mathrm{m}$.

On $19^{\text {th }}$ day an average thickness of epithelium in the control group was $42.36 \mu \mathrm{m}(10.77 \%$ of entire cornea thickness), Bowman's membrane $7.33 \mu \mathrm{m}$ $(1.64 \%)$, stroma $334.97 \mu \mathrm{m}(84.86 \%)$, Descemet's membrane $3.73 \mu \mathrm{m}(1.01 \%)$, endothelium $6.49 \mu \mathrm{m}$ (1.65\%), entire $394.48 \mu \mathrm{m}$.
On 19th day an average thickness of epithelium in the experimental group was $47.91 \mu \mathrm{m}(18.62 \%$ of entire cornea thickness), Bowman's membrane 6.21 $\mu \mathrm{m}(2.45 \%)$, stroma $185.12 \mu \mathrm{m}$ (75.68\%), Descemet's membrane $2.85 \mu \mathrm{m}(1.22 \%)$, endothelium $7.14 \mu \mathrm{m}$ $(2.86 \%)$, entire $273.92 \mu \mathrm{m}$.

Showed no significant differences in the thickness of the layers of the cornea of the eye left and right, both from the same individual as well as within research groups.

Tables 2 and 3 present thickness of each layer and the entire thickness of cornea in both groups and percentage of the various elements of the cornea in relation to its thickness.

\section{Discussion}

Administration of caffeine may generate disorders both in an organ of vision and a whole organism. From several dozen years it has been known, that high doses of caffeine have a negative influence on both women and laboratory animal's fertility. Caffeine is a factor of intrauterine growth retardation (IUGR). Relation between caffeine consumption and a risk of preterm birth and low birth weight is not still clear [14-16]. 
Table 2. Thickness of particular elements of the cornea $[\mu \mathrm{m}]$.

\begin{tabular}{|c|c|c|c|c|}
\hline & C.10 & E.10 & C.19 & E.19 \\
\hline $\mathrm{AE}$ & $13.00^{* / * *}$ & 14.34 & 42.36 & 47.91 \\
\hline $\mathrm{BM}$ & $2.54^{* / * *}$ & 3.87 & 7.33 & 6.21 \\
\hline $\mathrm{M}$ & $250.6^{* / * *}$ & 101.38 & $334.97^{* *}$ & 185.12 \\
\hline $\mathrm{DM}$ & 3.3 & 3.05 & $3.73^{* *}$ & 2.85 \\
\hline $\mathrm{PE}$ & $5.1^{* * * *}$ & 4.46 & 6.49 & 7.15 \\
\hline $\mathrm{CT}$ & $275.89^{* / * *}$ & 129.02 & $394.48^{* *}$ & 237.93 \\
\hline
\end{tabular}

* - significant difference between control groups $(\mathrm{p}<0.01)$.

** - significant difference between control and experimental groups $(\mathrm{p}<0.01)$.

Nevertheless, caffeine consumption together with smoking and alcohol drinking may have an influence on birth weight [17]. Moreover, synergism between caffeine and smoking or alcohol drinking significantly increases the number of spontaneous abortion [18]. It has also been shown, that drinking of two cups of coffee may lead to decrease of blood flow through placenta. Vessels contraction induced by caffeine, leads to tissues necrosis, due to hypoxia and ischemia [19]. Caffeine may, as well, influence behavior of healthy embryos in third trimester, especially breathing activity but also sleep and motor abilities [20].

During prenatal period caffeine may lead to improper development of many organs causing for example delayed neural tube closure [21], craniofacial and limb malformations, cleft palate [22,23], cardiovascular system malformations [12], the thymus involution and defects of skeletal system [24].

In organ of vision caffeine causes an increase of intraocular pressure not resulting in changes in outflow through the trabecular meshwork [25], having, however, an influence on epithelial cells of ciliary body [26]. It also causes multiple decrease of ocular blood flow [27]. Moreover, it increases blood vessel resistance and decreases blood flow in the human optic nerve head and choroid-retina, what may lead to disorders of retina development [28]. Few research that have been made, indicate a damaging effects of caffeine on some of the structures of a developing eye, particularly on cornea. Caffeine administered to pregnant rats during organogenesis $\left(9^{\text {th }}-21^{\text {st }}\right.$ day of pregnancy) does not cause macroscopic changes in embryos' corneas, but morphological changes could have been observed in some of the corneas. Changes were specially intensified in the group which had been given the highest dose of caffeine $(100 \mathrm{mg} / \mathrm{kg} / \mathrm{d})$ and they concerned multilayered endothelial cellular proliferation with hyperchromasia and polymorphism, increased stromal cells mitotic activity, focal morphological changes, and corneal swelling in the injured segments with irregular and widely separated destruc-
Table 3. Percentage of the various elements of the cornea in relation to its thickness [\%]

\begin{tabular}{|c|c|c|c|c|}
\hline & C.10 & L.10 & C.19 & L.19 \\
\hline ALi & $4.84^{* / * *}$ & 11.57 & $10.78^{* *}$ & 18.4 \\
\hline BM & $0.92^{* * *}$ & 4.32 & $1.86^{* *}$ & 2.35 \\
\hline M & $90.95^{* * * *}$ & 78.2 & $84.7^{* *}$ & 75.21 \\
\hline DM & $1.33^{* * *}$ & 2.39 & 1.01 & 1.22 \\
\hline PE & $1.96^{* * * *}$ & 3.19 & $1.65^{* *}$ & 2.82 \\
\hline
\end{tabular}

* - significant difference between control groups $(\mathrm{p}<0.01)$.

** - significant difference between control and experimental groups $(\mathrm{p}<0.01)$

tive stromal fibers. In the above mentioned group on 30th day after the birth irregular, polimorphic endothelial cells, with numerous vacuoles and agenezia of those cells were observed [10]. In the present study, caffeine was administered to chicken embryos during optic vesicle formation (stage 9/10 according to Hamburger-Hamilton). Dose was determined experimentally for a single chicken teratogenic dose- $3.5 \mathrm{mg} / \mathrm{egg}$ [12]. Based on several studies, the teratogenic dose of caffeine for certain animal species was found. However, these doses can not be applied to human, animal studies are a good way to assess the potential effect of caffeine on the human body. The present study focuses on the effect of caffeine on the morphometry of developing chicken cornea. At the light microscopic level, the reduction in total corneal thickness and stromal thickness in the experimental groups, compared with control groups, both in the $10^{\text {th }}$ as well as in the $19^{\text {th }}$ day of incubation, has been noted. Moreover, statistically significant increase in the percentage of endothelial thickness in the total thickness of the cornea was observed. Probably it is related to swelling of these cells, which would confirm the results of earlier studies [10]. During the physiological development of the cornea, the percentage of anterior epithelial and Bowman's membrane thickness in total corneal thickness increases, and other layers decreased. Nevertheless, in the experimental groups, only the percentage of anterior epithelial thickness of the total corneal thickness increased.

In humans, because of rapid caffeine metabolism, it is not teratogen. However, it is assumed, that caffeine is co-teratogen. It means that use of teratogens, such as alcohol, cocaine or some drugs, causes congenital malformations [29]. Caffeine does not seem to have a harmful influence on a development, if its consumption is small and controled. Materno-fetal vasoconstrictions that lead to ischemia-induced malformations could occur even in moderate doses, if caffeine is taken along with alcohol, tobacco, and vasoconstrictive or antimigraine medications. 
This is why, restricted caffeine consumption, to 300 $\mathrm{mg} / \mathrm{d}$ which is an equivalent of 2-3 cups of coffee, is advised during pregnancy. Not only does it refer to pregnant women, but also breast-feeding mothers, since the caffeine is also present in milk $[29,30]$.

The results of the following research indicate a negative influence of caffeine on corneal development. Conclusions from that experiment may give a new vision on patomechanism of innate opacification of the cornea.

Acknowledgments: The authors would like to thank Professor Andrzej Kulig, the head of the Department of Clinical Pathology of Institute of Polish Mother's Health in Lodz, for making "KIDNEY" software available.

\section{References}

[1] Bartel H. Embriologia medyczna. Wyd.I., Warszawa: Wydawnictwo Lekarskie PZWL; 2009.

[2] Bartel H. Embriologia. Wyd IV., Warszawa: Wydawnictwo Lekarskie PZWL; 1995.

[3] Carlson BM. Human Embryology and Developmental Biology. $3^{\text {rd }}$ ed., St. Louis: Mosby; 2004.

[4] Niżankowska MH. Podstawy okulistyki. wyd. 2, Wrocław: Volumed; 2000.

[5] Aldridge A, Bailey J, Neims AH. The disposition of caffeine during and after pregnancy. Semin Perinatol. 1981;5:310314.

[ 6] Graham DM. Caffeine-its identity, dietary sources, intake and biological effects. Nutr Rev. 1978;36:97-102.

[7] Jiritano L, Bortolotti A, Gaspari F, Bonati M. Caffeine disposition after oral administration to pregnant rats. Xenobiotica. 1985;15:1045-1051.

[ 8] Knutti R, Rothweiler H, Schlatter C. The effect of pregnancy on the pharmacokinetics of caffeine. Arch Toxicol. 1982;5:187-192.

[ 9] Weathersbee PS, Lodge JR. Caffeine: its direct and indirect influence on reproduction. J Reprod Med. 1977;19:55-63.

[10] Evereklioglu C, Sari I, Alasehirli B et al. High dose of caffeine administered to pregnant rats causes histopathological changes in the cornea of newborn pups. Med Sci Monit. 2003;9:168-73.

[11] Hamburger V, Hamilton HL. A series of normal stages in the development of the chick embryo. J Morphol. 1951;88:49-92.

[12] Bruvere HJ, Nishikawa T, Uno H, Gilbert JE, Gilbert EF. Pulmonary stenosis with ventricular septal defect, common aorticopulmonary trunk, and dextroposition of the aorta: morfologic and qualitative physiologic effect in caffein-treated chick embryos. Teratology. 1983;27(2):197-206.

[13] Klimek I, Kałużyński A, Kulig A, Szymczak W, Ambroziak R. Glomerular basement membrane thinning in children. Anal Quant Cytol Histol. 2006;5: 269-280.
[14] Fortier I, Marcoux S, Beaulac-Baillargeon L. Relation of caffeine intake during pregnancy to intrauterine growth retardation and preterm birth. Am J Epidemiol. 1993;137:931-940.

[15] McDonald AD, Amstrong BG, Sloan M. Cigarette, alcohol, and coffee consumption and prematurity. Am J Public Health. 1992;82:87-90.

[16] Caan BJ, Goldhaber MK. Caffeinated beverages and low birthweight: a case-control study. Am J Public Health. 1989;79:1299-1300.

[17] Bech BH, Obel C, Henriksen TB, Olsen J. Effect of reducing caffeine intake on birth weight and length of gestation: randomised controlled trial. BMJ. 2007;334;409.

[18] Armstrong BG, McDonald AD, Sloan M. Cigarette, alcohol, and coffee consumption and spontaneous abortion. Am $J$ Public Health. 1992;82:85-87.

[19] Kirkinen P, Jouppila P, Koivula A. The effect of caffeine on placental and fetal blood flow in human pregnancy. Am J Obstet Gynecol 1983;147:939-942.

[20] Devoe LD, Murray C, Youssif A, Arnaud M. Maternal caffeine consumption and fetal behavior in normal thirdtrimester pregnancy. Am J Obstet Gynecol. 1993;168:11051112.

[21] Wilkinson JM, Pollard I. In utero exposure to caffeine causes delayed neural tube closure in rat embryos. Teratog Carcinog Mutagen. 1994;14:205-211.

[22] Bartel H, Gnacikowska M. Badania histopatologiczne nad wpływem kofeiny na rozwój zarodkowy kończyn myszy. Folia Morphol (Warsz). 1972;2:193-200.

[23] Scott WJ. Caffeine-induced limb malformations: description of malformations and quantitation of placental transfer. Teratology. 1983;28:427-435.

[24] Matsuoka R, Uno H, Tanaka H. Caffeine induces cardiac and other malformations in the rat. Am J Med Genet. 1987;3:433443.

[25] Kurata K, Fujimoto H, Tsukuda R, Suzuki T, Ando T, Tokuriki M. Aqueous humor dynamics in beagle dogs with caffeineinduced ocular hypertension. JVMS. 1998;60:737-739.

[26] Kurata K, Maeda M, Nishida E. Relationship between caffeineinduced ocular hypertension and ultrastructure changes of nonpigmented ciliary epithelial cells in rats. J Toxicol Sci. 1997;22:447-454.

[27] Lotfi K, Grunwald JE. The acute effect of caffeine on the human macular circulation. Invest Ophthalmol Vis Sci. 1991;32:3028-3032.

[28] Okuno T, Sugiyama T, Tominaga M, Kojima S, Ikeda T, Effects of caffeine on microcirculation of the human ocular fundus. Jpn J Ophthalmol. 2002;46:170-176.

[29] Ross C, Persaud T. Cardiovascular primordium of the rat embryo following in utero exposure to alcohol and caffeine. CJC. 1986;2(3):160-163.

[30] Caffeine and pregnancy. FDA Drug Bull. 1980;10:19-20.

[31] Nawrot P, Jordan S, Eastwood J, Rotstein J, Hugenholtz A, Feeley M. Effects of caffeine on human health. Food Addit Contam. 2003;20(1):1-30.

Submitted: 25 March, 2010 Accepted after reviews: 28 May, 2010 